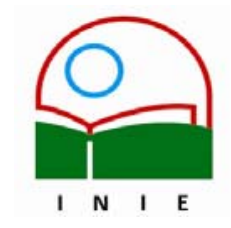

Universidad de Costa Rica

Facultad de Educación

Instituto de Investigación en Educación

ACTUALIDADES INVESTIGATIVAS EN EDUCACION

\title{
LA COMPRENSIÓN AUDITIVA: DEFINICIÓN, IMPORTANCIA, CARACTERÍSTICAS, PROCESOS, MATERIALES Y ACTIVIDADES
}

\section{Patricia Córdoba Cubillo ${ }^{1}$ Rossina Coto Keith ${ }^{2}$ Marlene Ramírez Salas ${ }^{3}$}

\begin{abstract}
Resumen: Este artículo pertenece a una serie de escritos que son producto de un proyecto de investigación sobre la enseñanza y el aprendizaje de la destreza auditiva en la clase de inglés de los colegios públicos de Costa Rica. El mismo se concentra en la destreza en sí: definición, importancia, características, procesos, materiales y actividades que se emplean para la enseñanza de la destreza auditiva en el aula.
\end{abstract}

\section{Palabras clave: ENSEÑANZA/ APRENDIZAJE/ DESTREZA AUDITIVA/ INSTRUCCIÓN/ LENGUA EXTRANJERA/MATERIALES/ ACTIVIDADES/}

\begin{abstract}
This article belongs to a series of articles that are the result of a research project about the teaching and learning of the listening skill in English classes in public high schools in Costa Rica. It is focused on the skill itself: its definition, its importance, its characteristics, its processes, its materials and its activities used in the teaching of the listening skill in the classroom.
\end{abstract}

Key Words: TEACHING/ LEARNING/ LISTENING SKILL/ INSTRUCTION/ FOREIGN LANGUAGE/ PROCESSES/ MATERIALS/ ACTIVITIES/

Históricamente, diferentes métodos de enseñanza han promovido la destreza auditiva en el aula; sin embargo, la investigación de esta destreza estuvo hasta hace pocas décadas relegada en los estudios, tanto de la lengua materna como de la lengua extranjera. De hecho, hasta hace muy poco la destreza auditiva no se consideraba una destreza separada e independiente, sino que siempre era puesta en función de su contraparte: la destreza oral; fenómeno también presente en la lectura en relación con la escritura. Efectivamente, por mucho tiempo los diferentes académicos e investigadores no consideraron que la destreza auditiva tuviera sus propias y en muchos casos, características particulares, propósitos y funciones.

\footnotetext{
${ }^{1}$ Magíster en la Enseñanza del Inglés como Lengua Extranjera; Licenciatura en Lingüística, Bachiller en Inglés, Profesora de Enseñanza Media en el ramo de Inglés, todos los títulos de la Universidad de Costa Rica. Profesora de la Escuela de Lenguas Modernas de la Universidad de Costa Rica. Correo electrónico: pcordoba@racsa.co.cr

${ }^{2}$ Maestría en la Enseñanza del Inglés como Segunda Lengua de la University of Northern lowa. Bachiller en Inglés de la Universidad de Costa Rica. Profesora de la Escuela de Lenguas Modernas de la misma universidad. Correo electrónico: rossinacoto@yahoo.com

${ }^{3}$ Master en la Enseñanza del Inglés como Lengua Extranjera de Southern Illinois University. Bachiller en Inglés de la Universidad de Costa Rica. Labora para la Universidad de Costa Rica desde 1993 en la Escuela de Lenguas Modernas impartiendo cursos a nivel de Bachillerato, Licenciatura y Maestría. Correo electrónico: marami@racsa.co.cr
}

Artículo recibido: 16 de mayo, 2005

Aprobado: 27 de iunio, 2005 


\section{¿Qué es la comprensión auditiva?}

Es prácticamente imposible tener una definición única sobre la comprensión auditiva. $A$ manera de ejemplo, Dunkel (1991, p. 43) menciona el artículo "A Content Analysis of Fifty Definitions of Listening", mediante el cual Glenn, analizó 34 diferentes definiciones presentadas en variados textos y encontró que, de hecho, no existe una definición universalmente aceptada.

Para ilustrar este punto, se presentan a continuación dos definiciones totalmente diferentes. Hace 20 años, Wipf en el artículo "Strategies for Teaching Second Language Listening Comprehension" definió la escucha como:

un proceso mental invisible, lo que lo hace difícil de describir. Las personas que escuchan deben discriminar entre los diferentes sonidos, comprender el vocabulario y las estructuras gramaticales, interpretar el énfasis y la intención, y retener e interpretar todo esto tanto dentro del contexto inmediato como de un contexto socio-cultural más amplio. (Wipf, 1984, p. 345)

En esta definición, si bien es cierto, se hace referencia al aspecto socio-cultural, el énfasis refleja las tendencias existentes hasta hace muy poco en cuanto a los idiomas, en las cuales se daba mucho más importancia a los aspectos fonológicos, léxicos y estructurales del idioma, y no a su componente socio-cultural, tan importante hoy en día.

Ya en la presente década, Rost define la escucha como un proceso de recibir lo que el emisor en realidad expresa (la orientación receptiva); construir y representar el significado (la orientación constructiva); negociar el significado con el emisor y responder (la orientación colaborativa); y crear significado a través de la participación, la imaginación y la empatía (la orientación transformativa). La escucha es un proceso de interpretación activo y complejo en el cual la persona que escucha establece una relación entre lo que escucha y lo que es ya conocido para él o ella. (Rost, 2002, p. 13)

En esta definición, se nota como el enfoque ha ido cambiando para dar cabida al aspecto social del lenguaje, especialmente a la importancia de la interacción entre el emisor y el receptor.

Sin embargo, por ser una explicación que complementa la anterior, la definición de comprensión auditiva que se usará a través de esta investigación, es la que acuñó James en 1984: 
...no es una destreza, sino una serie de destrezas marcadas por el hecho de involucrar la percepción auditiva de signos orales [además]...no es pasiva. Una persona puede oír algo, pero no estar escuchando...es absolutamente necesaria para cualquier otra labor que se realice con el lenguaje, especialmente para poder hablar y aún para poder escribir. (p. 129).

Esta descripción encarna tres hechos fundamentales:

1. Para lograr escuchar se deben interpretar sonidos producidos oralmente, lo que a su vez, implica que esta tiene que distinguir los fonemas de la lengua, o sea las unidades más pequeñas del idioma. Es esto lo que permite a la persona saber que, cuando escucha alguna expresión, ésta se manifiesta en una lengua y no en otra.

2. El hecho de escuchar es una destreza activa y no pasiva, (como se creía hasta la década de los 70 , aproximadamente) por lo que cuando una persona está escuchando, debe activar una serie de procesos mentales que le permiten comprender lo que se está diciendo.

3. Oír no es lo mismo que escuchar; lo que significa que para poder escuchar la persona tiene que concentrarse en lo que se está diciendo para poder descifrarlo e interpretarlo.

Efectivamente, la comprensión auditiva involucra una serie de aspectos que van desde lo más sencillo, o sea la comprensión del fonema, hasta otros aspectos paralingüísticos más complejos como el significado de lo que se está escuchando, además de la entonación, el énfasis y la velocidad con que se enuncia el mensaje, por ejemplo.

\section{Importancia de la comprensión auditiva}

Se podría decir que la destreza auditiva tiene tanta o más importancia que la destreza oral, dado que la una no funciona sin la otra, ya que hablar por el hecho de hablar, no constituye mayor mérito si lo que decimos no es recibido por otra persona. En este sentido escuchar se convierte en un componente social fundamental para prácticamente todo ser humano, exceptuando quizás las personas que no cuentan con el sentido del oído. De hecho, es importante recordar que por muchos años y, aún hasta la fecha, la tradición oral de los pueblos fue más importante que la tradición escrita, que es relativamente reciente. Sobre esto, Brown y Yule en su libro Teaching the Spoken Language (1983) se refieren a la conversación con fines de interacción (interactional talk) y a la conversación con fines 
transaccionales (transactional talk). El primer término señala el aspecto meramente social del lenguaje, o sea a la relación que se da entre dos o más personas cuando hablan y responden solamente para entablar un vínculo social (por ejemplo, cuando se habla de aspectos triviales con una persona en la fila del banco: el clima, la longitud de la fila, el estado del país, etc.). El segundo término describe el proceso por medio del cual entablamos una conversación para obtener y dar la información que necesitamos sobre algún tema. Como es lógico, estos dos términos representan "lo que es de hecho un continuo, de los aspectos sociales a los aspectos informativos de la comprensión de escucha" (Anderson y Lynch, 2002, p. 5).

Dado que en el área de la enseñanza de una segunda lengua existe muy poca investigación sobre la importancia y función de la comprensión de escucha, mucha de la teoría existente se basa en experiencias y teorías obtenidas durante el estudio de la adquisición de la lengua materna. Aunque tal situación es válida y ha aportado mucho al conocimiento, para el aprendiz de una segunda lengua existe una serie de problemas adicionales porque la persona debe tratar de comprender un mensaje en una lengua que está en proceso de aprender.

Es importante, sin embargo, notar algunos aspectos que diferentes investigadores han mencionado sobre la trascendencia de la comprensión de escucha, tanto en la lengua materna como en una segunda lengua. Krashen (1981), por ejemplo, estima que la comprensión juega un papel central y predominante en el proceso de aprendizaje de una lengua (p. 101). Esta es una perspectiva fundamental para el propósito de esta investigación, ya que lo que las autoras desean realizar es una serie de materiales de escucha que permitan al docente de secundaria tener más y mejores herramientas que permitan al estudiante ser más competente en el idioma inglés.

Muchos autores, tales como Dunkel (1986), Feyten (199l) y Anderson y Lynch (2002), entre otros, coinciden en que así como el infante atraviesa en sus primeros meses de vida por un "período silencioso" en su lengua materna, durante el cual recibe una gran cantidad de estímulo (lo que en inglés se denomina "input") sin producir lenguaje adulto, de la misma manera, la persona que se enfrenta a una segunda lengua bien podría beneficiarse de este período silencioso, durante el cual, estaría en contacto con el idioma, pero no se vería forzada a producirlo. Estos mismos autores indican que aún cuando el infante haya iniciado su producción oral, éste comprende más de lo que expresa, lo cual también se aplica en el aprendizaje de una segunda lengua. Esta posición motivó la implementación de diferentes modelos o enfoques para la enseñanza de una segunda lengua: el Modelo del Monitor 
(Monitor Model), el Modelo del Procesamiento de la Información (Information Processing Model), el Modelo de Interacción (Interaction Model), o el Método Natural (Natural Approach). En efecto, Feyten (199l) considera que la persona llega a completar gran parte de su proceso de adquisición de la lengua durante los primeros cinco años de vida en los cuales depende casi exclusivamente de lo que escucha (p. 174).

Byrnes (1984, pp. 318-319), explica esta posición claramente cuando dice que,

la comprensión auditiva precede la producción en todos los casos del aprendizaje de un idioma, y no puede haber producción a menos que se dé el estímulo lingüístico (linguistic input) y, que éste, a su vez, se convierta en material comprensible (comprehensible intake) para la persona que escucha. La comprensión es importante no sólo porque precede la producción lógica y cronológicamente, sino especialmente porque parece ser el mecanismo básico por medio del cual se internalizan las reglas del lenguaje.

Otra de las razones por las que la comprensión de escucha es de primordial importancia es que los seres humanos pasamos una gran cantidad, sino la mayor parte, de nuestra vida escuchando. Brown (1980, p. 39), por ejemplo, aduce que la comprensión auditiva es el modo de aprendizaje más eficaz, hasta por lo menos el sexto grado de la educación primaria, y que alrededor del $60 \%$ del tiempo lectivo de un estudiante se invierte en escuchar. Aunque no existen estudios publicados, es de suponer que un porcentaje similar ocurre también en el hogar, si tomamos en cuenta la cantidad de tiempo que los niños invierten en escuchar las órdenes e instrucciones de sus padres y otros adultos que cuiden de ellos, y el tiempo que invierten frente al televisor. Más adelante, durante la vida adulta, tanto en la vida social como profesional, la comprensión auditiva seguirá jugando un papel fundamental, ya que la persona invertirá mucho de su tiempo en escuchar a otras personas: en el trabajo, en seminarios, en eventos sociales y religiosos, entre otros. Como en la adquisición de la lengua materna, la comprensión auditiva es importante no sólo en las fases iniciales del aprendizaje de una segunda lengua, sino también en las etapas más avanzadas del proceso. Por ejemplo, Powers (1985, citado en Dunkel, 1991, p. 437) descubrió que los estudiantes que son sobresalientes en la comprensión auditiva obtienen mejores resultados (de 500 o más puntos en la escala antigua) en el TOEFL, el examen de inglés como lengua extranjera que toda persona que aspire a estudiar en alguna universidad canadiense o estadounidense debe tomar. 
Por otro lado, Winitz (citado en Dunkel, 1986) considera que la enseñanza de la comprensión de escucha debe ser el enfoque principal en el aula porque:

1. las reglas de la lengua se adquieren con más facilidad y exactitud por medio de la inferencia;

2. la adquisición de una lengua es primordialmente un proceso implícito e inconsciente por parte del estudiante;

3. la capacidad oral se desarrolla cuando existe suficiente formación dirigida a la comprensión. (p.99)

\section{Algunas características de la comprensión auditiva}

En la práctica educativa, las cuatro habilidades básicas se dividen en destrezas productivas: hablar y escribir, y en habilidades receptivas: leer y escuchar. Aunque esta clasificación es aún válida, como se puede constatar en prácticamente todo texto de metodología de la enseñanza, la concepción de lo que es receptivo o productivo ha cambiado. En el pasado, se creía que las habilidades receptivas no involucraban mayor esfuerzo y que la demanda cognitiva se presentaba casi en su totalidad al escribir y al hablar. Hoy se sabe que, aunque receptivas, tanto la comprensión de lectura como la comprensión auditiva requieren de una serie de procesos cognitivos sin los cuales la persona no podría dar sentido a lo que lee o escucha. Sobre esto Lynch y Mendelsohn (2002, p. 193) escriben que "hoy en día reconocemos que la capacidad auditiva es un proceso 'activo' y que las personas que son buenas al escuchar son tan activas como la persona que envía el mensaje".

Estos procesos cognitivos involucrados al leer o al escuchar encierran una serie de características que en muchas ocasiones, pero no siempre, comparten. Entre las características que estas habilidades comparten cabe mencionar las siguientes:

$>$ se necesita conocer el código lingüístico tanto para leer como para lograr escuchar de forma exitosa;

$>$ en ambas destrezas, la información se procesa en algunos casos de forma secuencial, de la mínima unidad al texto completo;

$>$ tanto el acto de leer como el de escuchar requieren la interpretación del mensaje y el conocimiento previo que la persona que escucha o lea tenga sobre el tema que se trata en la interacción o texto (schemata);

$>$ ambas actividades involucran la solución de problemas que se deben resolver, basándose en lo que se escucha o lee y en el conocimiento previo; 
cuando una persona lee o escucha, él o ella crea una serie de imágenes que coadyuvan en la comprensión del texto (Lynch y Mendelsohn, 2002, pp. 193-194; Omaggio, 2001, pp. 177-178)

Por otro lado, existe una serie de características exclusivas de la destreza auditiva:

$>$ lo que una persona escucha es, la mayoría de las veces, de un carácter efímero, por lo cual, generalmente, la persona no puede revisar lo escuchado y reevaluarlo, como sí ocurre en la lectura;

$>$ la comprensión de escucha requiere, en gran medida, el uso de la memoria, ya que la persona debe almacenar la información para poder responder a ella;

$>$ el escuchar involucra una serie de aspectos que el acto de leer no posee, tales como el énfasis, la entonación, el ritmo, el volumen y otros;

$>$ en el mensaje oral se encuentra una serie de formas no gramaticales, reducciones, eliminaciones, repeticiones, pausas, correcciones, redundancias y otros fenómenos que, por lo general, no se presentan en el mensaje escrito, por lo que la persona que escucha debe dar sentido al mensaje, aún cuando este no sea del todo claro y completo;

$>$ en muchos casos, existe la necesidad de procesar y responder de forma inmediata;

$>$ por lo general, la persona que escucha pierde la concentración rápidamente, lo que provoca que se "pierda" en el mensaje y luego no pueda responder apropiadamente;

$>$ en muchas ocasiones, el mensaje oral va acompañado de una serie de ruidos (música, otras conversaciones, bocinas, altavoces, por ejemplo) que interfieren con el mensaje; por lo tanto, la persona que escucha debe eliminar lo que no sirve y utilizar lo que sí es importante (Mendelsohn y Rubin, 1995, p. 8, Thompson, 1995, pp.35-36, Buck, 1995, pp. 114-115; Omaggio, 2001, pp. 178-179, Byrnes, 1984, pp. 317-319, Lynch y Mendelsohn, 2002, pp. 193-194).

\section{¿Cómo escuchamos?}

Como en muchos otros aspectos del diario vivir, el acto de escuchar sigue un proceso que es esencial, si queremos ser buenos receptores del mensaje. Galvin (1988) estima que este proceso requiere de cuatro pasos fundamentales. El primer paso es la recepción (receiving) y consiste en poner nuestro sentido del oído a trabajar. En este primer, paso la persona "decide" escuchar, o lo que es lo mismo, la persona empieza a clasificar entre lo que constituye únicamente "ruido" y lo que él o ella realmente desea o debe escuchar. E 
segundo paso es la interpretación. En este nivel, el receptor activa todas sus experiencias y vivencias para decodificar lo que acaba de escuchar. El paso número tres es la evaluación, el cual se basa en decidir qué hacer con el mensaje; por ejemplo: ¿Estoy o no de acuerdo?, ¿Requiero más información?, ¿Qué es lo importante de todo lo que he escuchado?, y otras preguntas similares. Por último, el paso final en este proceso es la respuesta, que no es necesariamente una respuesta oral, ya que puede ser perfectamente cualquier otra reacción tal como sonreír, asentir, realizar alguna otra acción o escribir algo, por ejemplo (Galvin, 1988, pp. 4-7). Este proceso fue ilustrado por una de las investigadoras de este proyecto en un artículo previo de la siguiente manera:

SITUACION: En un restaurante un empleado está conversando con su jefe sobre un estudio de mercadeo para un nuevo producto.

PASO 1: Jefe: "Tenemos que hacer un estudio de mercadeo para nuestro nuevo producto."

En esta etapa, el empleado activa su sentido del oído y elimina todo lo que no es importante tal como lo que otras personas están diciendo, la música del restaurante, el ruido de la calle, por ejemplo.

PASO 2: El empleado da sentido a lo que su jefe dijo, rescata lo importante del mensaje: "estudio de mercadeo" y "producto nuevo" y activa su conocimiento previo (schemata): la clase de estudio que se debe hacer; cómo hacerlo; el tipo de producto del que están hablando, y otros aspectos que le permitirán responder adecuadamente.

PASO 3: El empleado "estudia" la situación y decide cómo debe contestar o reaccionar a lo que su jefe acaba de decir: ¿Necesito hacer alguna pregunta?, ¿Debo decir si o debo decir no?, etc.

PASO 4: Empleado: "¡Claro que sí! Precisamente en eso estaba pensando. ¿Cuándo desea que empecemos?”

En este paso, el empleado también puede reaccionar de otros modos tales como un movimiento de la cabeza, tomar nota del mensaje, cambiar de tema si considera que no puede responder adecuadamente, o cualquier otro (Coto, 2002, p. 98).

Parte fundamental del proceso de comprensión auditiva es lo que se conoce como procesamiento de abajo hacia arriba (bottom-up processing), e interpretación de arriba hacia abajo (top-down processing). Estos procesos funcionan simultáneamente, permitiendo a la persona que escucha tener éxito en su tarea. El procesamiento de abajo hacia arriba (bottom-up) se inicia debido a una fuente externa, o sea por el mensaje mismo y consiste en "decodificar los sonidos que uno escucha de una forma lineal, de lo más pequeño (el 
fonema) a lo más complejo" (Nunan, 1997, p.1). En este tipo de procesamiento, la persona da sentido al mensaje, uniendo cada fonema para constituir palabras, que a su vez crean frases, las cuales dan forma a oraciones, y estas, a su vez, se unen para configurar el texto en su totalidad. Ejemplos de ejercicios que involucran el procesamiento de abajo hacia arriba, son los ejercicios en los cuales el estudiante debe discriminar entre sonidos, o escribir la palabra exacta en un ejercicio de completar los espacios en blanco. En este caso, a la persona que escucha se le ve como una grabadora porque asume que ella almacena los mensajes en una secuencia, de la misma manera que una grabadora (Anderson y Lynch, 2002, pp. 9-10).

La interpretación de arriba hacia abajo (top down) proviene de una fuente externa que impulsa al receptor del mensaje a construir o reconstruir activamente el significado del mismo, utilizando su conocimiento de la lengua, su conocimiento previo y analizando la situación: quién envía el mensaje, la relación entre emisor y receptor, el momento en que se da el mensaje y otros aspectos similares (Nunan, 1997, p. 1; Morley, 1991, p. 87). Ejercicios tales como poder identificar la idea principal de un mensaje o determinar el estado de ánimo de la persona que emite el mensaje, son ejemplos de ejercicios que corresponden a la interpretación de arriba hacia abajo.

Como se indicó anteriormente, estos dos modelos trabajan simultáneamente en la vida real y se compensan el uno al otro durante el proceso de escucha de un mensaje. Sin embargo, para efectos de la enseñanza de la comprensión auditiva, estos dos modelos pueden utilizarse por separado. Tal separación no solamente es recomendable en una clase de idioma extranjero, sino que también es fundamental para lograr que el estudiante pueda dar sentido al mensaje y así ser un participante activo de la interacción.

\section{Materiales y actividades}

En esta sección se discutirá el uso de actividades y materiales apropiados para desarrollar la comprensión auditiva durante las lecciones de idiomas. Es importante recalcar que los materiales y actividades que se usan en la clase de idiomas pueden atraer la atención de los estudiantes y, a la vez, aumentar la efectividad de la comprensión de escucha. Según Morley (1991, p. 89), el desarrollo de materiales y actividades para la comprensión de escucha está regido por tres principios básicos:

1. relevancia,

2. transferencia de situaciones reales,

3. orientación de tareas. 
La relevancia establece que, dependiendo de los intereses de los estudiantes, los contenidos de la lección de escucha y el resultado, el cual es el objetivo de la información, deben ser tan significativos como sea posible. Cuando las actividades no resultan interesantes ni apropiadas, éstas difícilmente atraerán su atención. Morley (1991, p. 90) considera que para las lecciones de comprensión de escucha, los profesores pueden usar materiales didácticos y de interés para los estudiantes, y adaptarlos mediante el desarrollo de actividades previas al ejercicio de comprensión de escucha y posteriores al mismo.

El principio de transferencia establece que cualquier material que sea relevante conlleve la reproducción de situaciones reales. Este hecho implica que los estudiantes deben aprender en clase, no solamente aspectos que funcionen en la escuela, sino aquellos que se puedan aplicar a la vida diaria. A continuación, se dan algunos ejemplos de actividades transferibles para estudiantes de diferentes edades. Para niños, Morley sugiere usar un cuento como el de Los Tres Ositos. Los niños escuchan la historia y luego escriben o hablan acerca de la misma. Lo que los estudiantes aprendan de este ejercicio puede transferirse a situaciones fuera del aula al aplicar la moraleja del cuento en diferentes momentos de sus vidas. Para los adolescentes, ella señala que cuando se esté estudiando el tema de preferencias o gustos, vean videos musicales y se evalúe la información que comprendieron. También dice que esto puede aplicarse fuera del aula, cuando los estudiantes asisten a un concierto o ven un video, por ejemplo. En el caso de los adultos, los estudiantes pueden escuchar la radio o ver cadenas de televisión y pueden parafrasear lo que entendieron. Fuera del aula, ellos podrían poner esto en práctica cuando escuchan o ven las noticias y hablan de las mismas con otras personas (Morley, 1991, p. 92).

Finalmente, el tercer principio se refiere a la orientación de tareas. Éste consiste en la combinación de dos tipos de trabajo: tareas en que se utiliza el idioma y tareas de análisis del idioma. Morley (1991) señala que el propósito de la tarea en que se utiliza el idioma es "dar a los estudiantes práctica en la escucha para obtener información y, especialmente, para hacer algo con esa información en forma inmediata" (p. 92), como cuando los estudiantes escuchan y transcriben, hacen un resumen o ejecutan acciones. Por otro lado, ella considera que las tareas de análisis del idioma "dan a los estudiantes oportunidades para analizar el uso y la estructura del idioma y desarrollar algunas estrategias personales que faciliten el aprendizaje" (p. 92). Un ejemplo de esta situación se da cuando los estudiantes analizan los rasgos del "habla rápida" o los marcadores del discurso. Cuando combinan estos dos tipos de actividades, los estudiantes construyen dos bases: una base de experiencias de contenido que sustenta el desarrollo del conocimiento previo en la lengua 
meta, y una base de experiencias que sustenta los encuentros comunicativos futuros. Con estas dos bases, los estudiantes incrementan el poder de predicción para futuros interludios comunicativos que les ayude a suponer o predecir rutinas del lenguaje y patrones en la lengua meta. Este aspecto práctico se conoce como aplicabilidad. Además, estas actividades ayudan a los estudiantes a incrementar su conocimiento y usarlo al interactuar con otras personas. Los materiales interesantes producirán mejores resultados y, por eso, los profesores deben prestar atención al planear y diseñar sus ejercicios de comprensión auditiva (Morley, 1991, p.92).

\section{Tipos de materiales}

La incorporación de materiales reales en la clase de idiomas es muy importante porque estos materiales ayudan a los estudiantes a conectar la práctica del aula con el mundo exterior. Nunan (1999, p. 212) y Morley (1991, p. 82) concuerdan en que los estudiantes deberían aprender en un contexto natural que les ayude a usar el idioma. Añaden que exponer a los estudiantes a textos auténticos es importante porque estos contienen vacilaciones, negociación de significado y traslapos que les ayudarán a enfrentarse a la comunicación real dentro y fuera del aula. Además, las fuentes auténticas son de interés para los estudiantes y hacen la clase más agradable. Es importante acotar que Nunan (1999, p. 212) enfatiza que la autenticidad es un tema relativo porque los profesores, algunas veces, adaptan los materiales para sus estudiantes y simplifican el vocabulario, las estructuras gramaticales y otros aspectos que podrían ser difíciles para ellos. En esos casos, los materiales no son "auténticos", pero sí son reales.

Con respecto al uso de materiales reales, Ur (1984, p. 2) sugiere una lista de posibles actividades de escucha basadas en situaciones reales. No todas estas actividades se centran exclusivamente en la comprensión auditiva; pero sí requieren de una comprensión general del acto comunicativo, en el cual la escucha juega un papel importante. Algunas de estas actividades son las siguientes:

>asistir a una celebración formal (boda, entrega de premios, etc.)

$>$ asistir a un seminario

$>$ ser evaluado oralmente acerca de un tema

$>$ conversar en una actividad social

$>$ hablar acerca del trabajo o la familia

$>$ intercambiar información

$>$ seguir las recomendaciones del doctor 
$>$ realizar entrevistas

$>$ escuchar una conferencia o discurso

$>$ escuchar mensajes por altavoces

Descuchar canciones

$>$ escuchar las noticias, reportes sobre el tiempo o anuncios

$>$ recibir instrucciones

$>$ ver una obra de teatro o un programa de televisión.

Sin embargo, se considera que el uso del discurso auténtico presenta un problema principal: el idioma es a menudo muy difícil, apropiado únicamente para niveles avanzados. Con respecto a la necesidad de usar material auténtico, Peterson (1991, p. 108) argumenta que la mayor parte de la escucha fuera del aula no se ajusta a un lenguaje sencillo. También añade que los estudiantes pueden entender mucho más de lo que pueden producir, y si se les provee de suficiente práctica, pueden manejar materiales auténticos sin mayor problema. Además considera que el ruido, las interrupciones, los gestos no-verbales, y el tono de voz usados en el habla auténtica ofrecen pistas para entender las relaciones de los hablantes, su propósito y motivación para hablar. También dice que la mayoría de textos auténticos son más redundantes y repetitivos que muchos otros textos basados en un guión específico. Es responsabilidad del profesor escoger los textos más apropiados para los estudiantes, dependiendo de su nivel, necesidades y los objetivos del curso. En suma, es importante no sólo escoger textos de escucha adecuados, sino también diseñar ejercicios apropiados para que el proceso de adquisición sea más fácil. Es importante indicar que para efectos de este proyecto, los materiales que se elaborarán serán reales, aunque no necesariamente auténticos.

\section{Tipos de ejercicios para la comprensión auditiva}

Los ejercicios de comprensión auditiva deben ofrecer una práctica significativa para atraer la atención de los estudiantes. Ur (1984, p. 47) dice que, como regla general, los profesores deben preparar a los estudiantes para la comprensión de escucha en la vida real. Además, los ejercicios de escucha son más efectivos, si se estructuran alrededor de una tarea. Es decir, se requiere que los estudiantes realicen alguna actividad en respuesta a lo que escuchan para demostrar su comprensión. Para realizar esto, Ur sugiere cuatro tipos de ejercicios:

1. escucha sin respuesta

2. escucha con respuestas cortas 
3. escucha con respuestas más largas

4. escucha como base para el estudio y discusión.

En el primer tipo de ejercicio, escucha sin respuesta, los estudiantes se enfrentan a grandes cantidades de texto acompañadas de algún tipo de apoyo visual. Algunos ejemplos son:

>escuchar y seguir un texto escrito

$>$ escuchar ayudado por materiales visuales

$>$ escuchar cuentos, canciones, películas y programas de televisión.

En el segundo tipo de ejercicios, escucha con respuesta corta, los estudiantes son expuestos a diálogos cortos $u$ oraciones para los cuales tienen que proveer respuestas breves, generalmente no verbales, en forma inmediata. Ejemplos de estos ejercicios son:

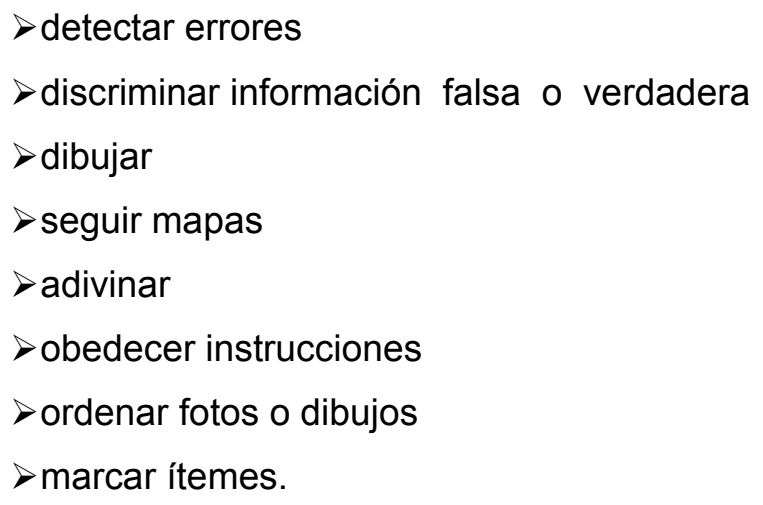

En el tercer tipo de ejercicios, los estudiantes contestan con respuestas más extensas que requieren un poco más de análisis de lo escuchado. Algunos tipos de ejercicios son:

$>$ contestar preguntas

$>$ completar espacios en blanco

$>$ parafrasear

$>$ predecir

$>$ repetir un texto

$>$ resumir

$>$ traducir.

En el cuarto tipo de ejercicio, la escucha como base para el estudio y discusión, se espera que los estudiantes entiendan lo que han escuchado para que lo analicen, interpreten y evalúen. Algunos ejemplos de estos ejercicios son: 
Descucha grupal en la cual tres o cuatro grupos de la misma clase escuchan una sola parte de la información. Esta información sólo se comprenderá en su totalidad cuando todos los grupos compartan el resto de la información (jigsaw)

$>$ solución de problemas.

En la clase de idioma, es importante combinar estos diferentes tipos de ejercicios. Por ejemplo, los estudiantes pueden escuchar un cuento y luego ordenar los dibujos de acuerdo con la secuencia del mismo. Ellos pueden también contestar preguntas sobre el cuento y discutir la moraleja o mensaje de este.

\section{Características de las actividades de comprensión auditiva}

Uno de los aspectos fundamentales de todo material de escucha por ser utilizado en el aula es el tipo de características específicas de las actividades que anteceden, acompañan y preceden el audio. Nunan (1999, p. 221) sugiere que una de las características que toda actividad de comprensión auditiva debe tener es un propósito pre-establecido para que sea eficaz en la clase de idiomas. Esta es una meta lingüística, puesto que el objetivo es mejorar la destreza de comprensión auditiva de los estudiantes. Si los estudiantes conocen por adelantado que tienen que producir cierto tipo de respuesta, inmediatamente tendrán un propósito cuando escuchen, y sabrán qué tipo de información deben esperar y cómo reaccionar a la misma. El profesor, por ejemplo, le puede pedir a los estudiantes que se enfoquen en los detalles específicos antes de que escuchen el texto. La segunda característica es que "la actividad debe motivar a los estudiantes, lo cual significa que debe estar bien preparada, ser entretenida y, a la vez, ser eficaz para el aprendizaje" (Ur, 1984, p. 27). Todo esto lleva a pensar que la mejor práctica de escucha se obtiene cuando los estudiantes la ejecutan exitosamente, y no cuando fracasan al realizarla. Como resultado, debe haber una selección léxica de acuerdo con el nivel de los estudiantes para que no encuentren la práctica o muy difícil o muy fácil. Las situaciones, además, deben ser lo suficientemente retadoras para que motiven a los estudiantes. De igual forma, si las actividades requieren de mucho equipo o constan de muchas páginas impresas, podrían perder su eficacia. Cuando las actividades son demasiado complejas, podrían demandar mucho tiempo de preparación y montaje en el aula, lo cual no siempre es rentable. Por último, los estudiantes deben recibir retroalimentación inmediata sobre su desempeño. Si la misma no se da en el momento, no debe retrasarse más de tres días porque, de lo contrario, pierde su razón de ser. Ur también recomienda proporcionar a los estudiantes las respuestas correctas antes de revisar el ejercicio con todo el grupo para que ellos puedan 
evaluar su propio trabajo; revisen el ejercicio paso a paso; analicen sus errores y aprendan de los mismos. El argumento más importante relacionado con la retroalimentación es su aspecto pedagógico: el valor del aprendizaje de cualquier ejercicio de escucha se incrementa, si hay una retroalimentación inmediata del profesor sobre el desempeño de los estudiantes (Ur, 1984, p. 28).

Al planear actividades de comprensión auditiva, se debe tomar en cuenta la secuencia o las etapas que guíen a los estudiantes hacia el desarrollo de esta habilidad. Estas etapas son:

$>$ pre-escucha,

$>$ durante la escucha

$>$ después de la escucha.

Durante la etapa previa a la escucha, o pre-escucha, se prepara a los estudiantes para escuchar. Ellos pueden escuchar una breve introducción al texto en que se podría incluir escuchar el título, la primera oración o varias frases. Luego, los estudiantes podrían inferir el contenido, el vocabulario, la estructura y la organización del texto. De esta forma, se estaría activando el conocimiento previo o esquemata (schemata). Es durante esta etapa, cuando se despierta el interés y la curiosidad de los estudiantes por lo que van a escuchar.

En la segunda etapa, durante la escucha, los estudiantes escuchan el texto para entender el mensaje y determinar la idea principal, sin prestarle atención a todos los detalles, como ocurre cuando se escuchan noticias, comerciales y entrevistas, entre otros. Los estudiantes pueden también examinar la información o los detalles de partes específicas incluidas en el texto, tales como escuchar el reporte del tiempo, seguir instrucciones dadas en la radio, o dar los nombres o el número de víctimas de un accidente automovilístico presentados en las noticias. Es importante señalar que para que los estudiantes desarrollen su comprensión auditiva deben escuchar el segmento de escucha, durante esta segunda etapa, varias veces. Al finalizar esta etapa, los estudiantes reciben retroalimentación cuando se revisan los ejercicios.

Por último, en la tercera etapa, después de la escucha, a través de la producción oral y escrita, los estudiantes opinan acerca del texto que escucharon en forma oral o escrita, al tiempo que expresan sus sentimientos y actitudes al realizar actividades como guiones, entrevistas, análisis de personajes, ensayos o discusiones, entre otras.

Estas tres etapas son importantes en todas las actividades de escucha y ayudan a los estudiantes a asimilar la información progresivamente.

Ur (1984, p. 11) argumenta que para los estudiantes de lenguas extranjeras hay algunos aspectos en la comprensión auditiva que son más fáciles de adquirir que otros. 
Mientras la mayoría necesitan mucho más práctica en algunas áreas específicas, en otras la escucha parece que ocurre instintivamente. Por ejemplo, el hecho de que algunos sonidos del inglés no se den en otras lenguas y de que existan diferentes acentos o patrones de entonación, hacen la adquisición de los mismos más difícil para los estudiantes del idioma inglés como lengua extranjera. Este aspecto del aprendizaje debe tomarse en cuenta al planear ejercicios específicos. Las necesidades de los estudiantes y los problemas de aprendizaje no deben ignorarse.

Como conclusión es importante recalcar que las actividades y materiales apropiados en la clase de idiomas son fundamentales porque atraen la atención de los estudiantes e incrementan la eficacia y la efectividad de la comprensión de escucha. No importa los materiales y actividades que se utilicen, si éstos no son relevantes, interesantes y apropiados para el nivel de los estudiantes, el objetivo primordial, que debe ser el buen desarrollo de la comprensión auditiva, no podrá lograrse.

\section{REFERENCIAS}

Anderson, A. and Lynch, T. (2002). Listening. Oxford: Oxford University Press.

Brown, G. and Yule, G. (1983). Teaching the Spoken Language. Cambridge: Cambridge University Press.

Byrnes, H. (1984). The Role of Listening Comprehension: A theoretical Base. Foreign Language Annals, 17(4), 317-329.

Buck, G. (1995). How to Become a Good Listening Teacher. In D. Mendelsohn and J. Rubin (Eds.). A Guide for the Teaching of Second Language Listening. (pp. 113-131). San Diego, California: Dominie Press.

Coto, R. (2002). Improving Listening Comprehension in a Second Language through the Use of Learning Strategies. Revista Káñina, 26(1), 97-105.

Dunkel, P. (1991). Listening in the Native and Second /Foreign Language: Toward an Integration of Research and Practice. TESOL Quarterly, 25(3), 431-457.

Feyten, C.M. (1991). The Power of Listening Ability: An Overlooked Dimension in Language Acquisition. The Modern Language Journal, 75 (ii), 173-180.

Galvin, K. (1988). Listening by Doing: Developing Effective Listening Skills. Lincolnwood, III.: National Textbook Company.

James, C.J. (1984). Are you Listening: The Practical Components of Listening Comprehension. Foreign Language Annals, 17(4), 339-342. 
Krashen, S. (1981) Second Language Acquistion and Second Language Learning. Oxford: Pergamon.

Lynch, T. and Mendelsohn, D. (2002). Listening. In Schmitt, Norbert (Ed.). An Introduction to Applied Linguistics. (pp.193-210). New York: Oxford.

Mendelsohn, D. \& Rubin, J. (1995). A Guide for the Teaching of Second Language Listening. San Diego, California: Dominie Press.

Morley, J. (1991). Listening Comprehension in Second/Foreign Language Instruction. In M. Celce-Murcia (Ed.), Teaching English as a Second or Foreign Language, (pp. 81106). Boston: Heinle y Heinle Publishers.

Nunan, D. (1999). Second Language Teaching and Learning. Boston: Heinle y Heinle Publishers.

Nunan, D. (1997). Listening in Language Learning. In The Language Teacher Online. Available October, 2004: http://jalt-publication.org/ttt/files/97/sep/nunan.html.

Omaggio Hadley, A. (2001). Teaching Language in Context. Third Edition. Boston: Heinle \& Heinle.

Peterson, P. (1991). A Synthesis of Methods for Interactive Listening. In M. Celce Murcia (Ed.), Teaching English as a Second or Foreign language, (pp. 106-110). Boston: Heinle y Heinle Publishers.

Richards, J. and Rodgers, T. (2001). Approaches and Methods in Language Teaching. London: Cambridge University Press.

Rost, M. (2002). Teaching and Researching Listening. London, UK: Longman.

Thompson, I. (1995). Assessment of Second/Foreign Language Listening Comprehension. In D. Mendelsohn and J. Rubin (Eds.), A Guide for the Teaching of Second Language Listening. (pp. 31-58). San Diego, California: Dominie Press, Inc.

Ur, P. (1984). Teaching Listening Comprehension. London: Cambridge University Press.

Wipf, J. (1984). Strategies for Teaching Second Language Listening Comprehension. Foreign Language Annals, 17, 345-48. 